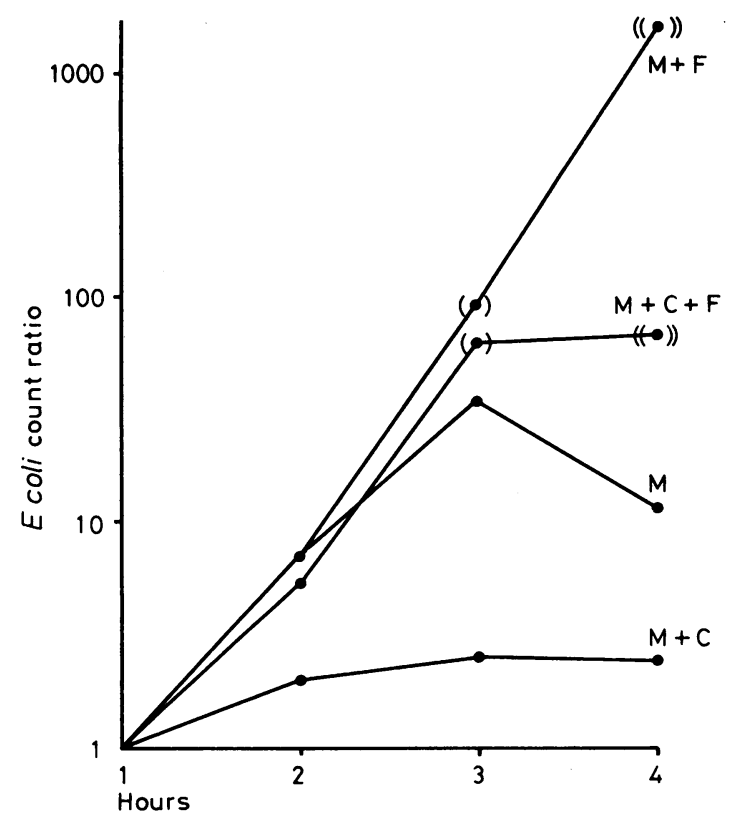

FIG 4-Effect of iron on bacterial growth in milk: $E$ coli count ratios after culture in aqueous-phase human milk (M) with or without iron $(F)$ and milk cells $(C)$ plotted against time of culture in hours. (Duplicate counts made of three samples from different mothers.) $E$ coli count ratios calculated from mean counts at each time/mean count at one hour. Values plotted as (9) included results greater than upper limit of countable bacteria $\left(5 \times 10^{5} / \mathrm{ml}\right.$, an assigned value); values plotted as ( (O) ) composed entirely of such threshold results.

adherence. ${ }^{12}$ The opsonisation of bacteria presumably depends on immunoglobulin and the classical pathway of complement, but that of $C$ albicans may depend on the alternative pathway. The less effective killing of $C$ albicans after phagocytosis by blood cells in milk medium as compared with blood cells in serum may result from inadequate complement activation, since killing is more complement-dependent than opsonisation. ${ }^{13}$
The less effective killing by milk cells may be caused by the phagocytosed lipid. The powerful humoral bacteriostatic effect of milk, dependent on IgA antibody and lactoferrin, is inactivated by the addition of iron. ${ }^{3}$ Our data suggest that the bactericidal effect of milk cells is also negligible when iron is added but could contribute significantly in the normal iron-free state, as is indicated by in-vivo experiments. ${ }^{6}$ These also suggest that the cells survive in the gastrointestinal tract long enough to produce an effect.

Epidemiological studies have shown that breast-fed babies are less susceptible to infection than artificially fed babies. ${ }^{1}$ Our results establish a further mechanism for this and strengthen the case against the use of iron-containing complementary feeds. ${ }^{3}$ There is little prospect of replacing cells in bovine-milk feeds, and our findings raise further problems in planning breast-milk banks.

We thank our colleagues, and the mothers at the Mothers' Hospital for the samples.

\section{References}

${ }^{1}$ Hanson, L A, and Winberg, J, Archives of Disease in Childhood, 1972, 47, 845.

${ }^{2}$ Bullen, C L, and Willis, A T B, British Medical fournal, 1971, 3, 338.

${ }^{3}$ Bullen, J J, in Acute Diarrhoea in Childhood, Ciba Foundation Symposium No 42, ed K Elliott. Amsterdam, Elsevier, 1976.

4 Smith, C, and Goldman, A, Pediatric Research, 1968, 2, 103.

5 Mohr, J A, Leu, R, and Mabry, W, fournal of Surgical Oncology, 1970, 2, 163.

${ }^{6}$ Pitt, J, et al, Pediatric Research, 1974, 8, 384.

${ }^{7}$ Dacie, J V, and Lewis, S M, Practical Haematology, 5th edn. London, Churchill Livingstone, 1975.

${ }^{8}$ Quie, P G, et al, fournal of Clinical Investigation, 1967, 46, 668.

${ }^{9}$ Lehrer, R I, and Cline, M J, Fournal of Bacteriology, 1969, 98, 996.

${ }^{10}$ Paape, M J, Schultze, W D, and Miller, R H, Fournal of Dairy Science, 1973, 56, 733.

11 Ammann, A J, and Stiehm, E R, Proceedings of the Society for Experimental Biology and Medicine, 1966, $122,1098$.

12 Ballow, M, et al, Clinical and Experimental Immunology, 1974, 18, 257.

${ }_{13}$ Yamamura, M, and Valdimarsson, H, Scandinavian fournal of Immunology, 1977, 6, 593.

(Accepted 28 March 1978)

\title{
Plasma arginine vasopressin concentrations and antidiuretic action of carbamazepine
}

\author{
W P STEPHENS, J Y COE, P H BAYLIS
}

British Medical fournal, 1978, 1, 1445-1447

\section{Summary and conclusions}

Twelve subjects given therapeutic doses of carbamazepine showed no change in their plasma electrolyte concentrations. Ten of the 12 had abnormal water metabolism, however, their ability to excrete water loads being

Good Hope General Hospital, Sutton Coldfield, West Midlands W P STEPHENS, MB, MRCP, medical registrar

J Y COE, MB, BS, senior house officer in medicine

Department of Medicine, Queen Elizabeth Hospital, Birmingham B15 2TH

P H BAYLIS, BSC, MRCP, senior registrar (present address: Department of Medicine, Veterans Administration Hospital, Indianapolis, USA) decreased. Plasma arginine vasopressin (AVP) concentrations fell while the subjects were taking the drug, indicating that the mechanism is unlikely to be increased secretion of antidiuretic hormone.

We suggest that the water-retaining property of carbamazepine is a physiological effect of the drug, mediated by increased renal sensitivity to normal plasma concentrations of AVP and resetting of osmoreceptors.

\section{Introduction}

The antidiuretic action of carbamazepine was recognised after reports on its use in diabetes insipidus and isolated cases of water intoxication during treatment with the drug. ${ }^{1}$ The mechanism of the action is not clear, and, whereas some reports suggest that asymptomatic electrolyte disturbances are fairly common, ${ }^{2}$ others suggest that they are rare. ${ }^{3}$ Previous studies have not shown whether carbamazepine affects the water metabolism of 
most patients or whether this is an idiosyncratic reaction of a minority. Many patients with water intoxication have been receiving several drugs, and the part played by drug interaction is not known. Water intoxication is a clinically important side effect of carbamazepine, as epilepsy may be aggravated by water retention, and trigeminal neuralgia and cardiovascular disease affect similar age groups.

The aims of our study were to establish whether abnormalities of water handling occurred in healthy subjects taking carbamazepine and to correlate any changes in water handling with plasma arginine vasopressin (AVP) concentrations. The ability to excrete a water load was assessed both before and during administration of carbamazepine. Changes in plasma AVP concentrations were measured during the water load test. Plasma sodium and AVP concentrations under standardised conditions (overnight water deprivation) were compared both before and during administration of the drug.

\section{Method}

Twelve young, healthy volunteers (nine men and three women, mean age 26 years) were deprived of water from $10 \mathrm{pm}$. At 9 am next day, blood was taken for measurement of plasma sodium and AVP concentrations and osmolality. The bladder was emptied. A standard water load of $20 \mathrm{ml} / \mathrm{kg}$ was given and urine collected every 15 minutes until peak diuresis. A constant water load was maintained by drinking a volume of water equal to the volume of urine expelled every 15 minutes. The urine flow rate eventually became steady, usually within three hours, and this was defined as the peak diuresis. Blood was taken at peak diuresis for measurement of plasma sodium, AVP concentrations, and osmolality. The volume and osmolality of each aliquot of urine were measured, and the free water clearance was calculated. For every water load test the maximum urine flow, maximum free water clearance, and minimum urine osmolality were calculated from the mean of three consecutive 15-minute samples at peak diuresis.

Each subject was given carbamazepine $600 \mathrm{mg} /$ day for seven days, and the water load test was repeated. Statistical comparisons were made using Student's paired $t$ test. To obtain the plasma AVP concentrations blood was taken with the subject sitting. The plasma was immediately separated and stored at $-10^{\circ} \mathrm{C}$ : AVP concentrations were measured by a radioimmunoassay technique. ${ }^{4}$

\section{Results}

Response to water load (table)-All twelve subjects completed the water load tests. While they were taking carbamazepine the ability of 10 to excrete the water load was greatly impaired as judged by reduced urine volumes and free water clearance and increased urine osmolality. The mean $( \pm S E$ of mean) reduction in maximum urine flow in the 12 subjects was $4.7 \pm 1.0 \mathrm{ml} / \mathrm{min}(P<0.001)$, the mean increase in minimum urine osmolality was $38.4 \pm 8.5 \mathrm{mmol}$ (mosmol)/ $\mathrm{kg}(\mathrm{P}<0.001)$, and the mean reduction in maximum free water clear- ance $4.8 \pm 0.8 \mathrm{ml} / \mathrm{min}(P<0.001)$. It is not clear why the water excretion of two subjects was not impaired. It is unlikely to have been the result of inadequate drug concentrations as the serum carbamazepine concentration in subject 12 was $5.0 \mathrm{mg} / 1(21 \mu \mathrm{mol} / \mathrm{l})$ before the test (therapeutic range $2-10 \mathrm{mg} / 1(8-42 \mu \mathrm{mol} / \mathrm{l})$ ).

Changes in plasma sodium and AVP concentrations after overnight $\stackrel{\text { w }}{-}$ water deprivation-There was no significant change in either plasma sodium concentration or osmolality when the subjects were taking 2 carbamazepine: Plasma AVP was measured in 10 subjects at 9 am. after overnight water deprivation; nine had lower concentrations while $\overrightarrow{=}$ taking the drug, and the water-load excretion of two of these was not $\stackrel{9}{-}$ impaired. The mean reduction in plasma AVP concentration was? $0.62 \pm 0.18 \mathrm{pmol} / 1(0.67+0.2 \mathrm{pg} / \mathrm{ml})(0.01>P>0.001)$

Changes in plasma AVP concentration during water load test (fig)After a water load plasma AVP concentrations fell. The mean fall $\mathbb{D}$ during the control test was $1.6 \pm 0.4 \mathrm{pmol} / 1(1.7 \pm 0.4 \mathrm{pg} / \mathrm{ml})$ and while taking carbamazepine $0.82 \pm 0.22 \mathrm{pmol} / \mathrm{l}(0.89 \pm 0.24 \mathrm{pg} / \mathrm{ml}) .^{\infty}$ After overnight water deprivation, however, the plasma AVP con- $\overrightarrow{0}$ centration was lower while subjects were taking the drug. AVPconcentrations at peak diuresis fell to similar levels both during the $\vec{\omega}$ control test and when the subjects were taking the drug. At peak $\mathrm{O}$ diuresis the mean plasma AVP concentration was $1.8 \pm 0 \cdot 14 \mathrm{pmol} / 1$ 극 $(2 \cdot 0 \pm 0 \cdot 15 \mathrm{pg} / \mathrm{ml})$ during the control test and $2 \cdot 0 \pm 0.29 \mathrm{pmol} / \mathrm{I}$. $(2.17 \pm 0.31 \mathrm{pg} / \mathrm{ml})$ while taking carbamazepine, an insignificant difference. Thus while subjects were taking carbamazepine their plasma AVP concentration was lower at the start of the water load test, dropped less, and reached a value at peak diuresis similar to $\vec{A}$

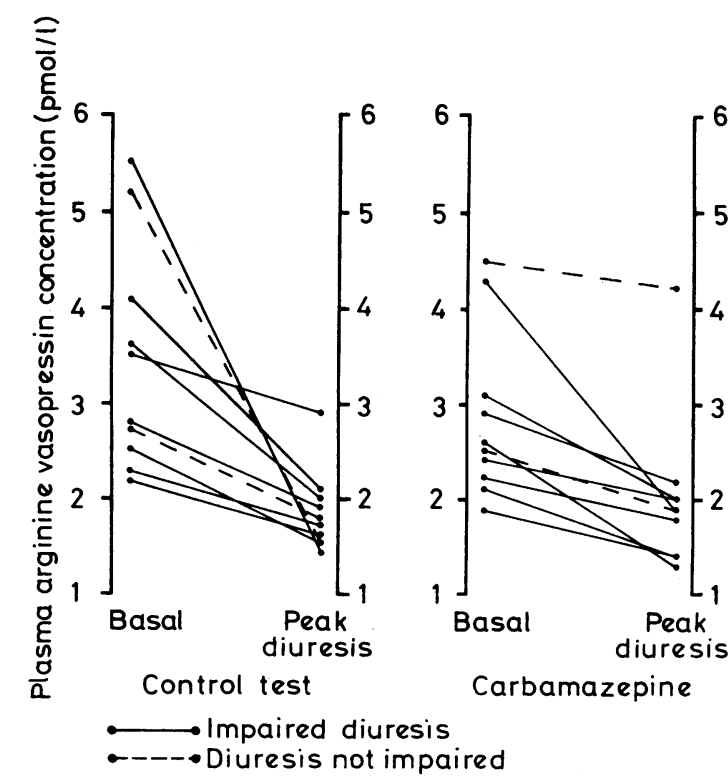

Changes in plasma AVP concentrations during water load test.

Plasma sodium concentrations and maximum urine volume, minimum urine osmolality, maximum free water clearance, and plasma arginine vasopressin $(A V P) \stackrel{N}{\text { C }}$ concentrations during water load test in 12 subjects. Measurements taken during control test and while subjects were receiving carbamazepine

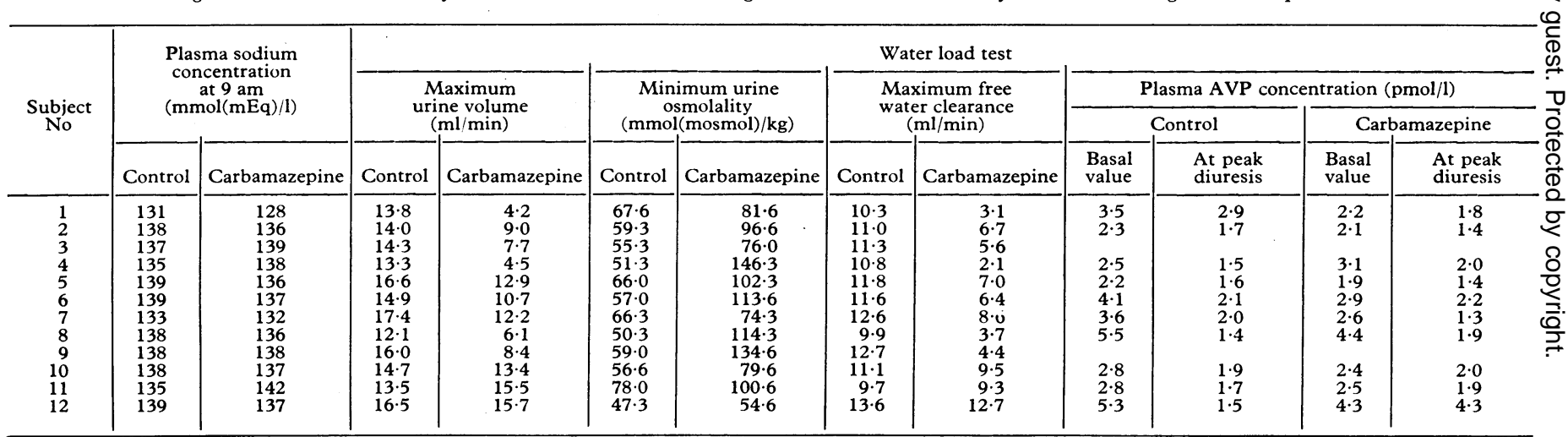

Conversion: SI to traditional units-Plasma AVP: $1 \mathrm{pmol} / 1 \approx 1.08 \mathrm{pg} / \mathrm{ml}$. 
that found during the control test. We have shown, however, that despite these similar AVP concentrations at peak diuresis there was grossly impaired diuresis in 10 of the 12 subjects.

\section{Discussion}

We found that there was impaired water handling in most subjects given therapeutic doses of carbamazepine. This is therefore a physiological effect of the drug and not dependent on idiosyncrasy or additional drug treatment. The drug's effect on water metabolism may be shown only by stressing the subjects with a water load and in standard conditions is not enough to alter the plasma electrolyte concentrations. Only a minority of patients would be expected to develop overt water intoxication.

Our results do not suggest that the mode of action is by stimulating the secretion of antidiuretic hormone. The basal plasma AVP concentrations fell while subjects took the drug, which agrees with the results of other studies." 6 We found no change in the plasma osmolality or electrolyte concentrations, which suggests that there is a fundamental resetting of osmoreceptors so that during periods of dehydration less antidiuretic hormone is secreted for a given plasma osmolality.

While diuresis is impaired during carbamazepine treatment, the plasma AVP concentration at peak diuresis is not altered when compared with that during a control water load test. This may be taken as further evidence against direct stimulation of the secretion of antidiuretic hormone. It suggests, however, that there is increased renal sensitivity to "normal" plasma concentrations of AVP. If the feedback mechanism via the osmoreceptors is intact then antidiuretic hormone secretion will be further reduced, which will compensate for the increased renal sensitivity. Therefore, if increased renal sensitivity to antidiuretic hormone is postulated there must also be a resetting of osmoreceptor regulation. This implies that when there is a large water load the osmoreceptors direct the hypothalamus to secrete an inappropriately high level of antidiuretic hormone. This argument assumes that the plasma AVP concentration at peak diuresis is not lower during carbamazepine medication simply because AVP secretion cannot be switched off any more.

There have been two reports of patients with symptomatic water intoxication due to carbamazepine, whose plasma AVP concentrations were inappropriately high yet returned to normal when the drug dosage was reduced. ${ }^{*} \times$ This would agree with disturbed autoregulation such as we postulate.

Our results suggest that the antidiuretic action of carbamazepine is due to a combination of resetting of osmoreceptors and increased renal sensitivity to antidiuretic hormone. The response of the osmoreceptors is blunted, so that during dehydration too little antidiuretic hormone is secreted and during overhydration too much is secreted. Under the influence of carbamazepine the osmoreceptors become lazy.

\section{References}

Stephens, W P, et al, British Medical fournal, 1977, 1, 754.

2 Henry, D A, et al, British Medical fournal, 1977, 1, 83.

${ }^{3}$ Helin, I, et al, British Medical fournal, 1977, 2, 558.

4 Baylis, P H, and Heath, D A, Clinical Endocrinology, 1977, 7, 91.

5 Meinders, A E, Cejka, V, and Robertson, G L, Clinical Science and Molecular Medicine, 1974, 47, 289.

6 Thomas, T H, et al, Clinical Science and Molecular Medicine, 1977, 53, 10P.

- Ashton, M G, et al, British Medical fournal, 1977, 1, 1134.

${ }^{8}$ Smith, N J, et al, British Medical fournal, 1977, 2, 804.

\title{
Haemophilia A home therapy in the United Kingdom 1975-6
}

\author{
PETER JONES， MAUREEN FEARNS， CHARLES FORBES， JOHN STUART
}

British Medical fournal, 1978, 1, 1447-1450

\section{Summary and conclusions}

Data on home treatment for patients with haemophilia A (factor VIII deficient haemophilia) were compiled for 1975 and 1976 from questionnaires answered by directors of haemophilia centres throughout the United Kingdom. There were 48 haemophilia centres in 1975 and 71 in 1976. The number of patients on or in training for home treatment increased from 267 to 488 in the two years, and a further 241 haemophiliacs were considered suitable for home therapy by the end of 1976. Apart from a small (but increasing) number of haemophiliacs on prophylactic treatment, most patients were on low-dose (250-500 units) on-demand regimens, using a mean of 20000

\footnotetext{
Newcastle Haemophilia Centre, Royal Victoria Infirmary, Newcastle upon Tyne

PETER JONES, MD, MRCP, consultant paediatrician

MAUREEN FEARNS, SRN, sister

Royal Infirmary, Glasgow

CHARLES FORBES, MD, FRCP, consultant physician

Queen Elizabeth Hospital, Birmingham

JOHN STUART, MD, FRCP, consultant haematologist
}

factor VIII units per patient per year in 1976. An estimated $55 \%$ of the blood product used for home therapy in the UK in 1976 was imported from commercial sources.

Despite the fact that the numbers of patients on home treatment have increased, so that about $60 \%$ of the potential population were receiving or being considered for home treatment in 1976, inadequacies in the service still remain. In some centres follow-up is clearly inadequate; about $15 \%$ of patients still rely on cryoprecipitate; and too little money has been invested in making the NHS self-sufficient in factor VIII production.

\section{Introduction}

The practice of training haemophilic patients to treat themselves at home with intravenous injections of factor VIII dates from the more widespread introduction of concentrated blood fractions in the mid 1960s. Before the discovery of cryoprecipitate in $1964^{1}$ these fractions were in short supply and usually reserved for surgery and the treatment of major complications in hospital, most haemophiliacs receiving fresh frozen plasma for the routine management of haemorrhage. The introduction of cryoprecipitate allowed outpatient treatment for all but the most severe bleeding episodes, and it was a logical step to train experienced patients to set up their own transfusions under supervision. Some haemophiliacs began to store cryoprecipitate 